\title{
DIVERSIDADE DE PIPRÍDEOS (AVES: PIPRIDAE) AMAZÔNICOS: SELEÇÃO SEXUAL, ECOLOGIA E EVOLUÇÃO
}

\author{
Marina Anciães ${ }^{1 *}$, Renata R. Durães ${ }^{2}$, Marconi C. Cerqueira ${ }^{3}$, Jaqueline R. Fortuna ${ }^{1}$, Natacha Sohn ${ }^{3}$, \\ Mario Cohn-Haft ${ }^{1} \&$ Izeni P. Farias ${ }^{4}$ \\ ${ }^{1}$ Coordenação de Pesquisa em Ecologia e Programa de Coleções e Acervos, Instituto Nacional de Pesquisas da Amazônia (INPA), Av. André Araújo \\ 2936, Aleixo, CEP 69060-001, Manaus - AM, Brasil. \\ ${ }^{2}$ Department of Biology and Whitney R. Harris World Ecology Center, University of Misouri-St. Louis, One University Boulevard, St. Louis, MO \\ 63121, EUA. \\ ${ }^{3}$ Programa de Pós-Graduação em Ecologia, INPA, Av. André Araújo 2936, Aleixo, CP 478, CEP 69077-970, Manaus - AM, Brasil. \\ ${ }^{4}$ Universidade Federal do Amazonas, Instituto de Ciências Biológicas, Departamento de Biologia, Estrada do Contorno 3000, Aleixo CEP $69077-000$ \\ - Manaus, AM - Brasil \\ *E-mail: marina.anciaes@gmail.com
}

\section{RESUMO}

Apresentamos uma revisão de estudos recentes sobre a história evolutiva de pássaros da família Pipridae. Os piprídeos estão expostos a forte pressão de seleção sexual, dado seu sistema reprodutivo de leques poligínicos. Com isso, damos ênfase aos efeitos da seleção sexual nos padrões de distribuição geográfica, utilização de hábitat e em aspectos do comportamento reprodutivo de populações e espécies, apresentando o sistema de Lepidothrix coronata como estudo de caso. Enquanto estudos filogeográficos indicam considerável estrutura genética entre populações de piprídeos, estudos em escala populacional investigam aspectos de seleção sexual, como os efeitos da organização social e espacial no desvio do sucesso reprodutivo entre machos, bem como sobre a evolução de cortes e plumagens elaboradas em machos. Estes dados indicam que a seleção sexual não somente é responsável pela elaboração morfológica e comportamental na família, como também contribui para a diferenciação entre histórias de vida em linhagens evolutivas. Investigar padrões de variação morfológica e comportamental, bem como aspectos da organização social e espacial em populações, portanto, nos permitirá compreender melhor a história demográfica das espécies da família. São escassos ainda estudos que comparem repertórios e sucesso reprodutivo entre machos, ou que investiguem como características do hábitat afetam as preferências de fêmeas em escala local. Em escala regional, estudos em zonas de contato, por exemplo, oferecem oportunidade para compreendermos a importância da variação em preferência de fêmeas e interações entre machos na disseminação de genes em introgressão. Assim, compreenderemos a relevância da seleção sexual para a formação de linhagens evolutivas independentes e, portanto, para a diversificação taxonômica na família.

Palavras-chave: Biogeografia, seleção sexual, poliginia de leques, tangarás, tamanho efetivo de populações.

\section{ABSTRACT}

MANAKIN (AVES: PIPRIDAE) DIVERSITY IN THE AMAZON: SEXUAL SELECTION, ECOLOGY AND EVOLUTION. We present a review of recent studies about the evolutionary history of birds of the family Pipridae, commonly known as manakins. Birds of this family usually face strong sexual selection, due to their polygynic lekking breeding system. We focused on the effects of sexual selection on geographical distribution patterns, habitat utilization and reproductive behavior in populations and species, using the species Lepidothrix coronata as a case study. Whereas phylogeographical studies point to considerable genetic structure among populations within species in the family, intra-population studies reveal how the strength of sexual selection, by means of variation in male reproductive success, is affected by social and spatial organization at leks, and how elaborate courtship displays and plumage coloration may evolve. Sexual selection is herein suggested not only to have resulted in great morphological and behavioral complexity in the family, but also to have contributed to the differentiation of life histories among different evolutionary lineages. Further studies of the variations in morphological and behavioral traits in the family, as well as studies on the social and spatial structure within populations, will provide a better understanding of the demographic history of these species. Few studies have correlated the behavioral repertoire of males with reproductive success or have evaluated the 
relevance of habitat characteristics to female preference, which will provide valuable data on a local scale. On a regional scale, studies focusing on contact zones would offer ways to understand, for example, the effects of variation in female preferences and male-male interactions on patterns of introgression. Taken together, these approaches would reveal the importance of sexual selection for the evolution of independent evolutionary lineages and, as such, for taxonomic diversification in the family.

Keywords: Biogeography, sexual selection, lek polygyny, piprids, effective population size.

\section{RESUMEN}

DIVERSIDAD DE SALTARINES (AVES: PIPRIDAE) AMAZÓNICOS: SELECCIÓN SEXUAL, ECOLOGÍA Y EVOLUCIÓN. Presentamos una revisión de estudios recientes sobre la historia evolutiva de las aves de la familia Pipridae, comúnmente conocidos como Saltarines. Los Piprídos están sometidos a una fuerte presión de selección sexual, debido a su sistema reproductivo de lek poligínicos. Por lo tanto, dimos énfasis a los efectos de la selección sexual sobre los patrones de distribución geográfica, uso de hábitat y comportamiento reproductivo de poblaciones y especies, presentando el sistema de Lepidothrix coronata como estudio de caso. Mientras que estudios filogeográficos muestran una estructura genética considerable entre poblaciones de especies de esta familia. Estudios a escala poblacional investigan aspectos de la selección sexual, como el efecto de la organización social y espacial sobre la desviación en el éxito reproductivo de los machos, así como la evolución de cortejos y plumajes elaborados en machos. Estos datos indican que la selección sexual no solamente es responsable de la complejidad morfológica y de comportamiento en la familia, sino que también contribuye a la diferenciación de historias de vida dentro de linajes evolutivos. Investigar patrones de variación morfológica y de comportamiento, así como aspectos de la organización social y espacial de las poblaciones, por lo tanto, nos permitirá comprender mejor la historia demográfica de las especies de la familia. Aun son escasos los estudios que comparan repertorios de cantos y éxito reproductivo entre machos, y cómo las características del hábitat influencian las preferencias de las hembras a escala local. A escala regional, estudios en zonas de contacto, por ejemplo, nos ofrecen una oportunidad para entender la importancia de la variación en las preferencias de las hembras y las interacciones entre machos en la diseminación de genes en introgresión. Del mismo modo, comprenderemos la relevancia de la selección sexual para la formación de linajes evolutivos independientes y, por lo tanto, para la diversificación taxonómica en la familia.

Palabras clave: Biogeografía, selección sexual, lek poliginicos, tangaras, tamaño efectivo de poblaciones.

\section{INTRODUÇÃO}

Os piprídeos (Aves: Pipridae) habitam ambientes florestais de toda a região neotropical. Estes pássaros são relativamente diversos taxonomicamente, representando cerca de 50 espécies, dependendo da classificação (Snow 2004). São frugívoros de sub-bosque, sendo sobretudo conhecidos pelo típico sistema reprodutivo de leques poligínico (Snow 1963a, Sick 1967). Neste sistema, machos mantém seus territórios agrupados e exibem danças nupciais elaboradas, acompanhadas de vocalizações especializadas e sons não vocais ("mecânicos", Prum 1998), para atrair um maior número de fêmeas, as quais não recebem recursos além do sêmen e se encarregam da nidificação e cuidado parental (Bradbury \& Gibson 1983, Andersson 1994, Prum 1998).
A evolução de leques está centrada em estratégias que maximizem o sucesso reprodutivo de fêmeas por facilitar o acesso e comparação entre machos, como quando estes se agregam espacialmente (Bradbury \& Gibson 1983, Höglund \& Alatalo 1995). Uma vez que a seleção de parceiros reprodutivos é facilitada em agregação, espera-se que a organização espacial, bem como a sincronia temporal em reprodução e as características sociais (ex., dominância entre machos) de leques influenciem também o desvio em sucesso reprodutivo entre machos, e, portanto, a magnitude da seleção sexual (Foster 1983, Shuster \& Wade 2003, Tori et al. 2008). A forte pressão de seleção sexual observada na família provavelmente explica o dimorfismo sexual acentuado da maioria das espécies, em que machos apresentam plumagens de cores vibrantes e fêmeas são esverdeadas (Snow 
1963a, Prum 1990, Snow 2004). Observa-se ainda considerável diversidade morfológica entre espécies de piprídeos, inclusive entre espécies proximamente aparentadas, o que tem sido atribuído a distintos mecanismos de seleção sexual por preferência de fêmeas (Prum 1997, revisão em Andersson 1994).

Espécies de piprídeos apresentam em geral amplas distribuições geográficas e densidades populacionais elevadas (Ridgely \& Tudor 1994, Snow 2004), sendo encontrada na região amazônica a maior riqueza de espécies (ca. 26) por bioma ou ecorregião do neotrópico (Anciães \& Peterson 2006). Na Amazônia, os piprídeos integram os exemplos clássicos de grupos de espécies, filogeneticamente próximas, com distribuições parapátricas, sendo estas muitas vezes delimitadas por rios das principais bacias hidrográficas da região (Haffer 1974). Este padrão, juntamente com a marcante diferenciação morfológica entre espécies revela uma excelente oportunidade para estudos sobre diversificação biológica em escala micro- e macroevolutiva, uma vez que diferenças em comportamentos de corte, incluindo vocalizações e sons mecânicos, bem como em plumagens ornamentais podem reforçar o isolamento reprodutivo entre populações divergentes (Andersson 1994, Prum 1997).

A considerável estrutura genética encontrada entre populações de piprídeos sugere relevância do desvio em sucesso reprodutivo entre machos para a história demográfica, e portanto para a filogeografia, de espécies da família (Cheviron et al. 2005, Francisco et al. 2006, 2007). Por fim, a presença de zonas de contato com introgressão genética mediada por variação em preferência de fêmeas (Brumfield et al. 2001, Stein \& Uy 2006) sugere uma contribuição marcante da seleção sexual na história evolutiva da família.

Propomos ilustrar como a compreensão de padrões biogeográficos, em escala regional, pode ser facilitada por estudos em escala populacional que enfatizem compreender as particularidades comportamentais em um grupo com características como distribuição de indivíduos agregada, variação social em uso espacial, exibição de cortes e sinais visuais elaborados e, sobretudo, desvio acentuado em sucesso reprodutivo entre machos. Apresentamos exemplos do sistema de Lepidothrix coronata, uma das cinco espécies representantes do gênero na Amazônia brasileira, com ampla distribuição geográfica e considerável variação em plumagem e também, possivelmente, em comportamento de corte.

\section{BIOGEOGRAFIA \\ DISTRIBUIÇÃO GEOGRÁFICA}

Os piprídeos distribuem-se por cerca de doisterços da região Neotropical, atingindo sua maior diversidade na região amazônica (Anciães \& Peterson 2006). Mais da metade das espécies da família são encontradas, sobretudo, ao norte do rio Negro e entre os rios Xingú e Purus, no Brasil, e na região entre os rios Madre de Dios, na Bolívia, e Marañon, ao norte do Peru. As regiões de maior diversidade de piprídeos na Amazônia coincidem, em linhas gerais, com as áreas de endemismo denominadas Imeri, Pará, Rondônia e Inambari designadas em Cracraft (1985), segundo resultados de Anciães \& Peterson (2006). Conforme descrito em Ridgely \& Tudor (1994), Sick (1997) e Snow (2004), os piprídeos habitam variados ambientes florestais e, na Amazônia, ocorrem em sua maioria em florestas de terra firme, sendo também encontrados em campinaranas (ex., Dixiphia pipra, Pipra rubrocapilla, Heterocercus, Neopelma chrysocephalum, Xenopipo), bem como em florestas alagáveis (ex., Heterocercus, Pipra filicauda e P. aureola). Adicionalmente, algumas espécies ocorrem em áreas sob influência de regiões extra-amazônicas, como os Andes (ex., Machaeropterus striolatus), montanhas da América central (ex., L. coronata), o Cerrado (ex., Chiroxiphia pareola) e a Mata Atlântica (ex., D. pipra).

\section{HISTÓRIA EVOLUTIVA}

A sistemática da família ainda encontra-se incompleta, havendo estudos complementares que apresentam relações filogenéticas nem sempre congruentes, e que não representam todos os táxons da família (Prum 1990, 1992, Rêgo et al. 2007). Porém, as relações entre espécies dos gêneros Pipra e Lepidothrix estão relativamente bem resolvidas, assim como o posicionamento basal do clado CorapipoMasius-Ilicura (Prum 1990, 1992; Cheviron et al. 2005, Rêgo et al. 2007).

Os rios e interflúvios da Amazônia delimitam a distribuição de várias espécies de piprídeos na região (ex., $P$. rubrocapilla e $P$. erythrocephala, $L$. iris e L. nattereri, L. coronata; Haffer 1992, Cracraft 
\& Prum 1988, Cheviron et al. 2005, Rêgo et al. 2007), reforçando as áreas de endemismo de grandes interflúvios descritas para muitas aves amazônicas (Haffer 1974, Chapman 1917, Sick 1967, Cracraft 1985, Capparella 1988, 1991). O número crescente de estudos indica que a história evolutiva da fauna amazônica não é explicada por um fator apenas, e que diferentes fatores (ex. barreira de rios, história geológica, variações climáticas do Quaternário, intrusões marinhas, revisão em Haffer e Prance 2001) influenciaram a diversificação em sistemas faunísticos distintos (Patton \& Silva 1998, Cohn-Haft 2000, Aleixo 2004, Cheviron et al. 2005). Padrões de diversificação taxonômica poderiam incluir ainda fatores pouco enfatizados em estudos sobre a evolução da biota amazônica, como diferenças ecológicas, relacionados à utilização do hábitat (MacArthur 1972, Endler 1977) e variações comportamentais que influenciem a comunicação intraespecífica, sobretudo durante a reprodução (Endler 1992, Andersson 1994).

A falta de conhecimento sobre a história evolutiva se explica, parcialmente, pelo fato que apenas recentemente a filogeografia molecular, ou história evolutiva de linhagens gênicas, entre populações de uma espécie (Avise 2000), começou a ser utilizada como ferramenta para o teste de hipóteses biogeográficas sobre a biota amazônica, incluindo anfíbios (Gascon et al. 1998, 2000), aves (Hackett 1996, Bates 2000, 2001, Bates et al. 1999, 2004, Cohn-Haft 2000, Marks et al. 2002, Aleixo 2004, Sardelli 2005) e mamíferos (Patton et al. 1994, 1997, 2000). Estes estudos avaliaram a história evolutiva de linhagens gênicas entre populações de uma ou várias espécies, enquanto poucos estudos com passeriformes (ex., Aleixo 2004, Cheviron et al. 2005) abordaram a história demográfica de populações, devido sobretudo à necessidade de se amostrar um grande número de indivíduos. Além de importantes para a compreensão de processos biogeográficos, estudos filogeográficos nos permitem compreender processos microevolutivos associados à diversificação de características ecológicas, morfológicas e comportamentais em espécies que, em última instância, afetam o desvio no sucesso reprodutivo entre machos de uma população (ex., Francisco et al. 2006, 2007).

O gênero Lepidothrix é composto por oito espécies reconhecidas atualmente, das quais seis são encontradas na região amazônica (Snow 2004). Estas espécies diferem no tamanho de suas distribuições e apresentam padrões de distribuição parapátrica entre espécies. Essas espécies também são distintas em morfologia e seu comportamento ainda relativamente pouco conhecido (Prum 1994, Snow 2004). Dada existência de hipóteses filogenéticas incluindo espécies do gênero, bem como gêneros próximos (Prum 1990, 1992; Rêgo et al. 2007; ver Cheviron et al. 2005), o gênero representa uma boa oportunidade para estudos em escala macro- e microevolutivas que tenham como objetivo elucidar aspectos não somente biogeográficos mas também associados à seleção sexual na família.

\section{NICHOS ECOLÓGICOS}

A modelagem de nichos ecológicos aplicada ao estudo de distribuições geográficas é uma ferramenta útil em biogeografia, reunindo aspectos históricos e ecológicos que determinam a distribuição de espécies (Soberón \& Peterson 2005). Assumindo que nichos ecológicos representam as associações das necessidades fisiológicas e a distribuição geográfica de espécies (sensu Grinnel 1917, 1924; as modificações de Hutchison 1957 e MacArthur 1972 incluem o papel de espécies em comunidades), estes são modelados a partir de dados climáticos, topográficos e da vegetação representativos dos pontos de ocorrência conhecidos para um determinado táxon. Alguns estudos indicam que para vários táxons, incluindo os piprídeos, nichos ecológicos são amplamente conservados entre espécies irmãs (Peterson et al. 1999, Rice et al. 2003, Martínez-Meyer et al. 2004; Anciães \& Peterson 2006), sugerindo que eventos de especiação comumente ocorrem na ausência de variações ecológicas. Exceções a esta generalização apresentam oportunidades para investigar as rápidas transições ecológicas.

Os piprídeos ocupam nichos ecológicos caracterizados sobretudo por elevadas temperaturas e precipitação, característico de florestas de planícies, com algumas espécies ocorrendo em condições mais frias e secas. Os casos extremos são representados por espécies que ocupam vertentes dos Andes (ex., Chiroxiphia boliviana) e áreas extremamente quentes e úmidas da Amazônia ocidental e Chocó (ex., Heterocercus aurantiivertex, Manacus vitellinus), segundo Anciães \& Peterson (em revisão). 
O clado formado por Corapipo, Masius e Ilicura (sensu Prum 1990, 1992) apresenta nichos amplamente conservados entre espécies, enquanto espécies do gênero Lepidothrix apresentam nichos relativamente diferenciados (Anciães \& Peterson, em revisão), sugerindo que mecanismos de diferenciação taxonômica em Lepidothrix podem estar associados à utilização de gradientes ecológicos ou a uma alta flexibilidade ambiental entre populações de suas espécies.

Porém, a freqüente similaridade em nichos ecológicos entre espécies irmãs da família, bem como a baixa ocupação da área de distribuição potencial observada em Anciães \& Peterson (em revisão), corroboram resultados de estudos moleculares (Rêgo et al. 2007, Cheviron et al. 2005) e indicam rios como barreiras à dispersão de piprídeos (Wallace 1852, Haffer 1974). A observação de que existe um fraco sinal filogenético em grupos de espécie de piprídeos amazônicos com distribuições sobrepostas (Rêgo et al. 2007) indica que fatores vicariantes são os principais delineadores das distribuições atuais de espécies da família, incluindo aqueles que envolvem diferenciação ecológica em alopatria. Modelos de gradiente ecológico (Endler 1977) entretanto não podem ser descartados em Lepidothrix, sendo necessários mais dados sobre variação ecológica, por exemplo, na região ao sul do rio Solimões na distribuição de $L$. coronata.

Uma vez que o gênero Lepidothrix representa uma exceção na família quanto ao padrão de diferenciação ecológica, mesmo dentro da bacia Amazônica, este grupo representa um caso exemplar para estudos sobre os efeitos da variação ecológica na diversificação taxonômica, bem como em processos microevolutivos como a origem e manutenção da variação em plumagem em $L$. coronata.

Associações entre o hábitat utilizado e a coloração da plumagem, por exemplo, vêm sendo indicadas como um fator importante na evolução morfológica em Pipridae e aves em geral (Endler \& Théry 1996, Uy \& Endler 2004, Stein \& Uy 2006a,b; Tori et al. 2008). Porém resultados recentes indicam fraca influência das condições ambientais na sinalização utilizada durante a comunicação intraespecífica em piprídeos do clado Corapipo-Masius-Ilicura (Anciães 2005, Anciães \& Prum 2008) e para saíras do gênero Tangara (Aves: Thraupidae, Stoddard \& Prum 2008). Assim, o hábitat utilizado para exibições poderia afetar a sinalização através do uso de palcos com coloração diferenciada ou através do comportamento de jardinagem, caso este modifique as características colorimétricas do substrato contra o qual indivíduos devam ser visualizados (ex., em Corapipo [Prum 1986], Masius [Prum \& Johnson 1997], e Manacus [Uy \& Endler 2004]).

\section{FILOGEOGRAFIA E HISTÓRIA DEMOGRÁFICA \\ $E M$ Lepidothrix coronata}

Entre as espécies do gênero, $L$. coronata possui a mais ampla distribuição geográfica (e de fato uma das mais amplas na família), além de apresentar um dos casos mais marcantes de variação geográfica em coloração de plumagem de machos (Hellmayr 1929, Snow 2004) e uma complexa história evolutiva (Cheviron et al. 2005, 2006).

Dados recentes (Cheviron et al. 2005) e deste estudo indicam uma possível área de contato entre linhagens distintas, com plumagens diferenciadas, em extensão consideravelmente maior do que aquela descrita em Hellmayr (1929, Figura 1). Estes resultados sugerem que a seleção sexual pode estar influenciando a distribuição de populações desta espécie, sobretudo ao sul do rio Solimões. Variações em preferência de fêmeas, por exemplo, poderiam explicar esta diferença em plumagem, conforme observado na zona de contato entre espécies de Manacus da América Central (Brumfield et al. 2001, Stein \& Uy 2006a).

Análises sobre a história demográfica da espécie (Tabela I) indicam que a fragmentação alopátrica e expansão demográfica explicam sua história evolutiva, tanto em clados formados por populações distribuídas perifericamente na Amazônia (Cheviron 2005), quanto em grupos de populações destes mesmos clados localizados na Amazônia brasileira. Utilizando clados definidos através de análises filogenéticas de Máxima Parcimônia e Máxima Verossimilhança, com 633pb do gene mitocondrial Cyt- $b$, estas análises indicam que os rios Negro e Japurá representam barreiras primárias (ex., associadas diretamente à causa da separação entre linhagens) à distribuição de populações. Resultados do presente estudo, aliados às informações contidas em Cheviron et al. (2005), indicam uma história evolutiva estável para grupos de populações delimitadas por esses rios. 

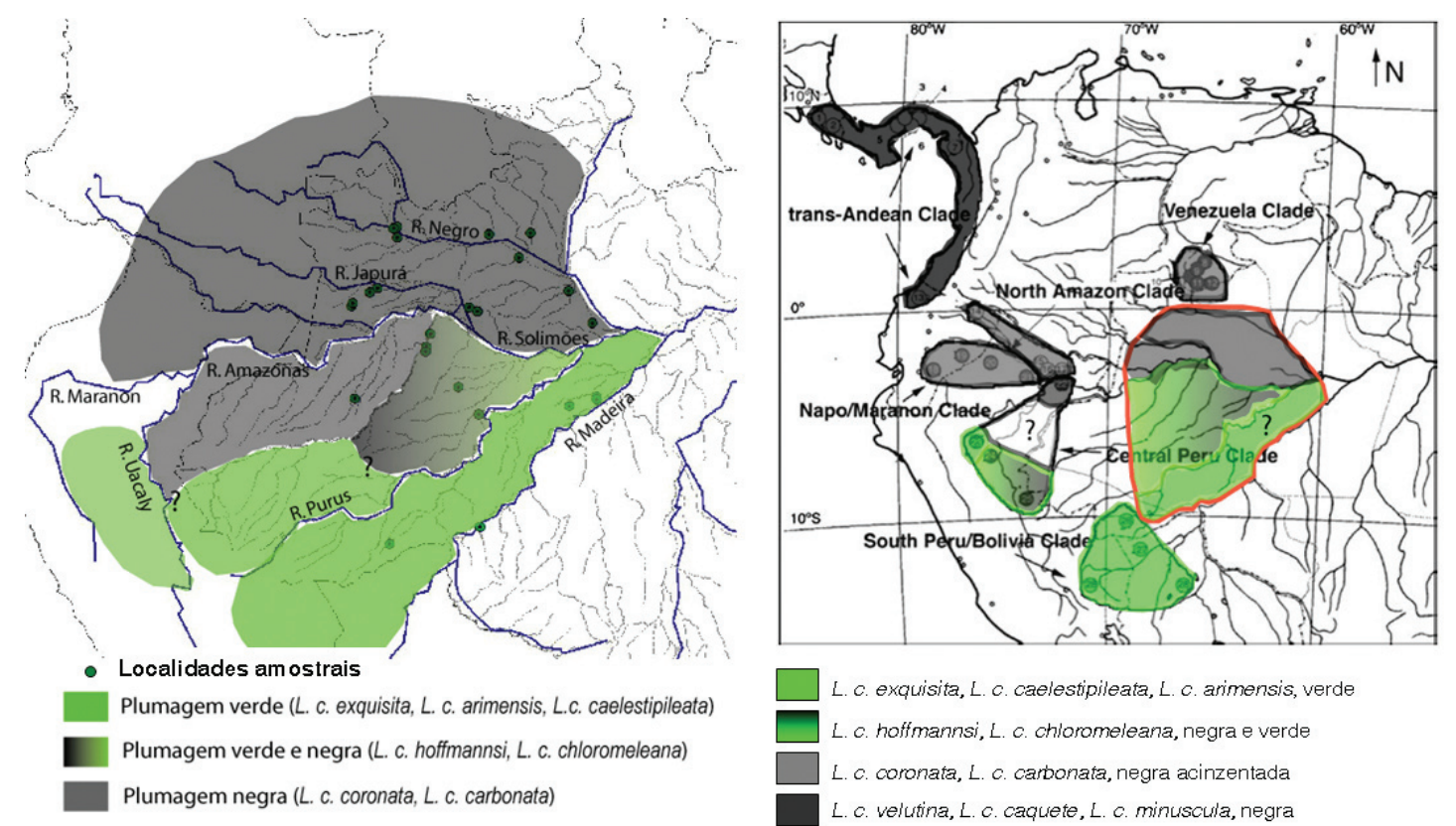

Figura 1. Distribuição de formas de plumagem de Lepidothrix coronata na Amazônia: (a) histórica, interpretado de Hellmayr (1929) e (b) atual, adaptado de Cheviron et al. 2005 e conforme o presente estudo (circundado em vermelho), reconstruído a partir de observações em campo e inspeção de peles de museu e suas etiquetas.

Figure 1. Distribution of plumages (a) interpreted from historical records (Hellmayr 1929) and (b) according to field observations and museum skins and labels (Cheviron et al. 2005, and present study, in red).

Por outro lado, o clado representado por populações de plumagens mistas (entre rios Ucayali no Peru, e Madeira, ao sul do Solimões) apresenta história de expansão demográfica recente, típica de distribuições ao longo de barreiras secundárias. Barreiras secundárias seriam resultantes por exemplo de isolamento de populações por fatores ecológicos e climáticos, seguido por colonização ou re-invasão de áreas adjacentes às barreiras após diferenciação em alopatria (revisão em Cheviron et al. 2005). Estes dados são compatíveis ainda com padrões genéticos esperados em zonas de contato, como aquela sugerida por Hellmayr (1929).

\section{SELEÇÃO SEXUAL EM POPULAÇÕES ESTRUTURA ESPACIAL E ORGANIZAÇÃO SOCIAL}

A evolução de leques está centrada em estratégias que maximizem o sucesso reprodutivo de fêmeas por facilitar o acesso e comparação entre machos, como quando estes se agregam espacialmente (Foster 1983, Höglund \& Alatalo 1995). Uma vez que leques são sistemas reprodutivos não baseados em recursos (Lill 1976, Bradbury \& Gibson 1983), a variação na qualidade de território entre machos deve ter pouca influência na escolha de fêmeas. Assim, leques oferecem uma boa oportunidade para estudos sobre os efeitos da distribuição e uso espacial na variação em sucesso reprodutivo, na ausência de variáveis como a qualidade territorial (Durães et al. 2007).

Uma característica marcante de sistemas de leques poligínicos é a grande diferença entre machos em seu sucesso reprodutivo (ex., Payne 1984, Mackenzie et al. 1995, e nos piprídeos Chiroxiphia, McDonald 1989, McDonald \& Potts 1994, Duval 2007; Pipra, Tori et al. 2008; ver também Durães et al. 2008), ainda que já tenham sido relatados casos de baixo desvio entre machos em outros sistemas (ex., Lanctot et al. 1997, Lank et al. 2002). Estudos recentes indicam que padrões de distribuição e uso espacial podem apresentar consequências diretas para o sucesso reprodutivo de indivíduos (ex., Formica et al. 2004). Hipóteses explicando tais efeitos incluem as características temporais, espaciais e sociais de leques. Assim, a sincronia reprodutiva e a agregação espacial entre fêmeas, bem como a distância entre leques e o nível de interações sociais e de hierarquias explicariam a variação em sucesso reprodutivo de machos em leques poligínicos (Foster 1983, Shuster \& Wade 2003).

Variações nas características espaciais e de uso de hábitat em piprídeos simpátricos da Amazônia 
Tabela I. Análises de variação genética e história demográfica dentro e entre clados (grupos de populações) definidos em análises filogenéticas: \% de distância genética entre haplótipos, no programa MEGA 4, estrutura genética (Fst, Nei 1987, no programa Arlequim 3.1.1.), diversidade nucleotídica (pi- $\pi$, Nei 1987, no programa MEGA 4), teste de expansão demográfica rápida (Fu’s Fs; $r$ e R2, Romis-Onsins \& Rozas 2002 e Harpending 1994, no programa DnaSP 4).

Table I. Analyses of genetic variation and demographic history within and among clades recovered in phylogenetic analyzes: \% genetic distance among haplotypes, in MEGA 4, genetic structure (Fst, Nei 1987, in Arlequim 3.1.1.), nucleotidic diversity (pi- $\pi$, Nei 1987, in MEGA 4), test of fast demographic expansion (Fu's Fs; r e R2, Romis-Onsins \& Rozas 2002 and Harpending 1994, in DnaSP 4).

\begin{tabular}{|c|c|c|c|c|c|c|c|c|c|c|}
\hline Comparação & n loc. & $\mathrm{n}$ indiv. & $\begin{array}{l}\text { \% Dist. Gen. } \\
\text { (SE) }\end{array}$ & Fst & $\operatorname{Pi}(\pi)(\mathrm{SE})$ & $\mathrm{r}$ & $P(\mathrm{r})$ & $\mathrm{R}_{2}$ & $P\left(\mathrm{R}_{2}\right)$ & Fu's Fs \\
\hline \multicolumn{11}{|l|}{ Dentro de clados } \\
\hline rio Negro mg. esquerda & 3 & 5 & $0.8(0.3)$ & - & $0.008(0.003)$ & 0.68 & 0.88 & 0.40 & 0.93 & 3.36 \\
\hline rio Negro mg. direita & 5 & 8 & $0.7(0.2)$ & - & $0.007(0.002)$ & 0.11 & 0.21 & 0.40 & 1.00 & -2.61 \\
\hline Interflúvio Juami-Japurá & 2 & 5 & $0.10(0.3)$ & - & $0.002(0.001)$ & 0.35 & 0.54 & 0.24 & 0.15 & -0.83 \\
\hline Interflúvio Juruá-Madeira & 6 & 12 & $0.2(0.1)$ & - & $0.002(0.001)$ & 0.75 & 0.96 & 0.28 & 0.74 & 0.43 \\
\hline Total & 16 & 30 & $0.2(0.1)$ & - & $0.027(0.005)$ & - & - & - & - & - \\
\hline \multicolumn{11}{|l|}{ Entre clados } \\
\hline rio Negro esq vs. rio Negro dir. & 8 & 13 & $1.3(0.5)$ & 0.45 & - & - & - & - & - & - \\
\hline $\begin{array}{l}\text { rio Japurá dir. vs. rio Solimões } \\
\text { dir. }\end{array}$ & 8 & 17 & $3.5(0.9)$ & 0.95 & - & - & - & - & - & - \\
\hline $\begin{array}{l}\text { (rio Japurá dir. + interflúvio } \\
\text { Juruá-Madeira) vs. } \\
\text { (rio Negro dir. + rio Negro esq.) }\end{array}$ & 16 & 30 & $4.1(0.9)$ & 0.61 & - & - & - & - & - & - \\
\hline
\end{tabular}

equatoriana (D. pipra, P. filicauda, L. coronata) explicaram a variação no sucesso reprodutivo entre machos, demonstrando como processos em escala populacional podem influenciar a variância em sucesso reprodutivo entre machos e, em última instância, a direção e magnitude da seleção sexual em escala evolutiva (Tori et al. 2008). Os resultados indicam que uma maior agregação de fêmeas, maior taxa de encontro de machos e maior dominância entre machos são associados a maiores desvios no sucesso reprodutivo entre esses.

Dentre os vários modelos, não exclusivos, propostos para explicar a evolução, e particularmente a distribuição espacial de leques (ex., Snow 1963a, Bradbury 1981, Bradbury \& Gibson 1983, Beehler \& Foster 1988, Westcott 1997, revisão em Andersson 1994), a hipótese de “hot-spots” (Bradbury \& Gibson 1983, Bradbury et al. 1986, 1989) tem sido investigada recentemente. Estudos avaliaram a associação entre a localização de leques e a disponibilidade de recursos, sejam estes fêmeas, como recursos dinâmicos (ex., Durães et al. 2007), ou alimento, como recurso estático (Ryder et al. 2006).

Ao investigar a disponibilidade de frutos componentes da dieta de piprídeos amazônicos (D. pipra, $P$. erythrocephala e $P$. filicauda), Ryder et al. (2006) demonstraram que leques dessas três espécies encon- travam-se em locais com maior biomassa de plantas e maior número de frutos maduros do que em locais sem leques. Tal estudo demonstrou assim que leques podem conter mais recursos alimentares, o que poderia atrair uma maior quantidade de fêmeas e contribuir para o sucesso reprodutivo dos machos.

Durães et al. (2007), entretanto, demonstraram que a distribuição de leques em $L$. coronata não está associada a locais com maior sobreposição de fêmeas. Apesar de leques da espécie serem encontrados em áreas de “hot-spots” de fêmeas, leques com maior número de machos localizavam-se fora destas áreas. O estudo sugere que a segregação espacial observada entre sexos seja explicada por preferência de hábitat diferenciada entre machos e fêmeas. Podemos esperar que a seleção de habitats em fêmeas seja mais importante no sentido de diminuir a predação dos ninhos, enquanto que em machos esteja mais direcionada para escolher ambientes adequados para a exibição sexual e que permitam a segregação ecológica entre diferentes espécies de piprídeos (Loiselle et al. 2007).

\section{COMPORTAMENTO DE CORTE}

EM Lepidothrix coronata

Os comportamentos de corte exibidos por machos de piprídeos em leques representam provavelmente 
uma das características mais marcantes da família (Darwin 1871, Snow 1963a, Sick 1967). O repertório comportamental de corte é variado entre as espécies de piprídeos, e contém informações filogenéticas que podem ser utilizadas para reconstruir a história evolutiva da família (Prum 1990, 1994, Bostwick 2000). Dessa forma descrições do comportamento de corte de espécies, bem sobre a variação geográfica entre populações podem auxiliar na compreensão da sistemática da família, e permitir inferências sobre processos de diversificação taxonômica através de seleção sexual. Estudos comparativos do comportamento de corte permitirão testes sobre fatores ecológicos que influenciem a evolução e a variação comportamental entre espécies e populações (Martins 1996).

Estudos comportamentais foram realizados recentemente em três populações distintas de $L$. coronata. A primeira população, do grupo L. c. coronata, foi estudada por três anos na Reserva Tiputini, Equador (R. Durães, em revisão); e as outras duas populações, do grupo L. c. carbonata, foram estudas na região do baixo rio Preto, margem esquerda do rio Negro (M.C. Cerqueira et al. dados não publicados), e no Parque Nacional do Jaú, margem direita do rio Negro (M. Anciães, observ. pess.). As observações indicam complexidade comportamental para a espécie, totalizando ca. 16 elementos, entre vôos estereotipados, vocalizações e posturas, usadas em contextos de exibições para fêmeas, interações entre machos, e defesa territorial entre os três estudos. Indicam ainda que o repertório de corte de $L$. coronata apresenta elementos exclusivos à espécie (ex., "gangorra", "bandeira"), bem como elementos compartilhados exclusivamente com outras espécies do gênero (ex., "giro lateral", "vôo S de costas") e elementos similares àqueles exibidos por outros gêneros (ex., "vôo borboleta“, "cambalhota“) (Tabela II, Figura 2).

Os resultados comportamentais apresentados corroboram observações anteriores (Prum 1990, 1992; Bostwick 2000) de que o comportamento de corte em piprídeos é diverso, apresentando sinal filogenético, e que cada espécie apresenta elementos exclusivos (i.e. autapomorfias). Assim, não somente podemos corroborar a monofilia do gênero, como podemos inferir que $L$. coronata está sujeita a forte pressão de seleção sexual. Estudos complementares sobre o repertório de corte de espécies do gênero permitirão avaliar ainda se a complexidade comportamental de $L$. coronata reflete o posicionamento filogenético basal em seu clado (formado por L. iris-L. nattereri-L. isidorei-L. coeruleocapilla, Cheviron et al. 2005), uma vez que um maior número de elementos comportamentais pode estar presente em linhagens mais antigas.

A comparação entre os repertórios observados nas três populações estudadas indica oito elementos em comum, quatro elementos observados somente em L. c. coronata, e outros quatro observados somente em L. c. carbonata, além de variações em frequência de exibição de alguns elementos em comum. Estudos adicionais são necessários para confirmação destes possíveis casos de variação geográfica no comportamento, bem como em frequência de exibição de elementos. A inclusão de mais populações permitirá ainda o teste comparativo entre a variação genética e comportamental na espécie. Estudos sobre variação geográfica em comportamento de corte em piprídeos ainda são escassos, mas apresentam potencial para estudos sobre os efeitos da seleção sexual na elaboração comportamental e divergência em história evolutiva entre populações. Diferença em comportamento entre populações de Corapipo altera distribuídas em vertentes opostas da América Central (Anciães 2005, Anciães \& Prum 2008), corroboram por exemplo a separação das duas formas (C. altera e C. heteroleuca), conforme sugerido por Prum (1990) com base em caracteres morfológicos da plumagem.

Durante as observações (58h) de Cerqueira e colaboradores, machos de L. c. carbonata defenderam territórios principalmente no meio da manhã e início da tarde, totalizando $97 \%$ do período de observações, embora exibições de corte tenham sido observadas somente em $14 \%$ desse período. Foram localizados três leques, distanciados entre si por 200 e $500 \mathrm{~m}$. As observações foram feitas em apenas um destes territórios, pertencente a um leque composto por quatro territórios, cujos centros se distanciavam por ca. de $40 \mathrm{~m}$. No território observado, machos se exibiram solitariamente ( $40 \%$ dos casos) e em grupos de até três machos com plumagem definitiva ( $60 \%$ dos casos) ou eventualmente um macho em plumagem pré-definitiva (indivíduos que podem ser sexualmente maduros, mas sem plumagem definitiva, típica de adultos). Indivíduos em plumagem verde, que não exibiram cortes, e representam possivelmente fêmeas, visitaram em frequências equivalentes exibições demachos solitários 
e em grupo. Os machos utilizaram cinco palcos neste território, os quais se distanciavam por cerca de 10m, mas se exibiram principalmente no palco central (em disposição espacial). A movimentação entre territórios deste leque foi frequente, e aparentemente em duas ocasiões, indivíduos se movimentaram para outro leque (inferido através de observação simultânea entre observadores em leques vizinhos). As observações de L. c. carbonata no Parque Nacional do Jaú foram feitas em dois territórios, pertencentes a leques distintos. As características espaciais de leques foram similares entre ambas as populações de $L$. c. carbonata, e entre esta e a população de $L$. $c$. coronata observada por Durães (em revisão).

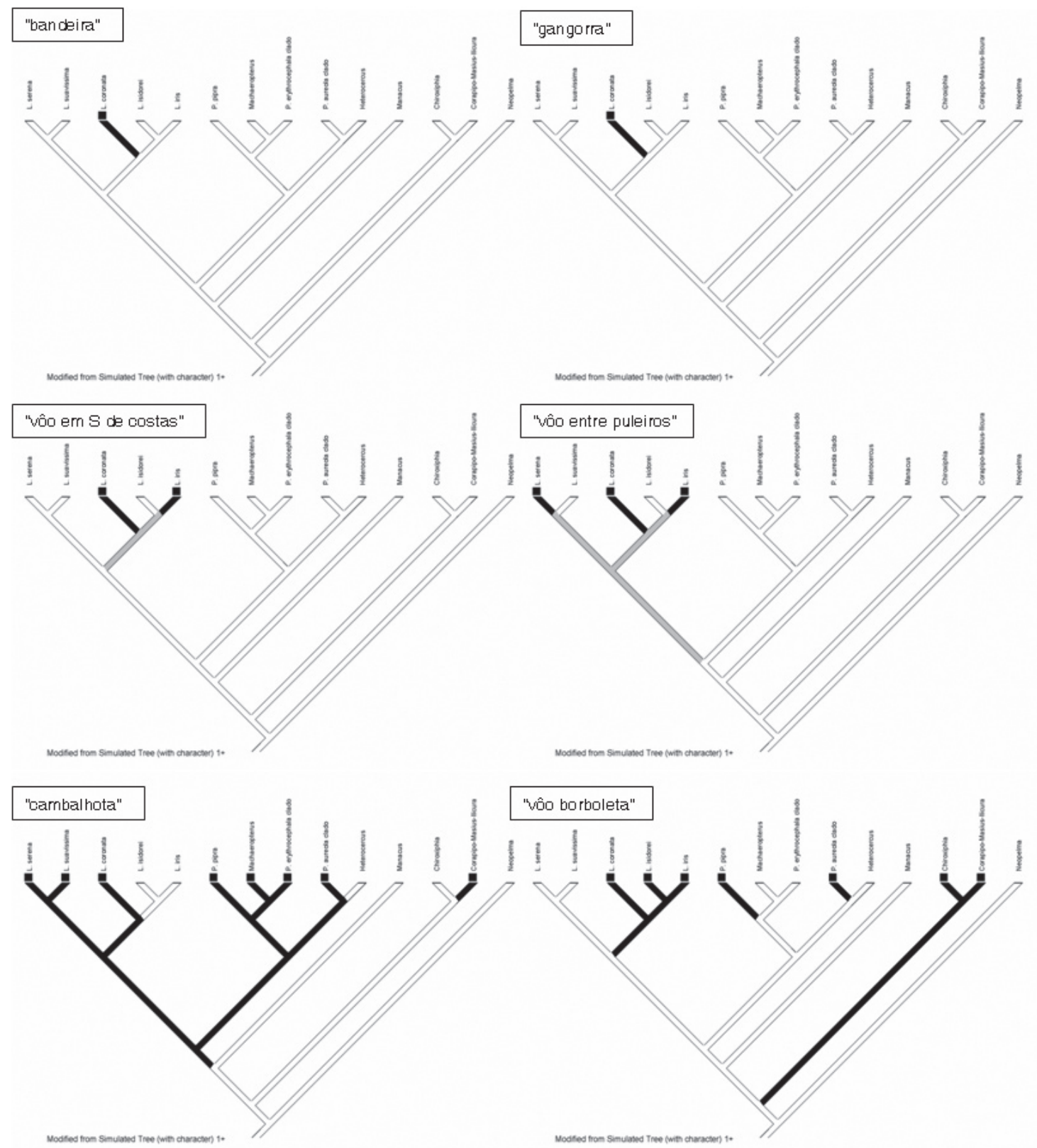

Figura 2. Reconstrução filogenética da evolução de elementos de corte (a) exclusivo de Lepidothrix coronata, (b) compartilhados entre espécies de Lepidothrix e (c) similares a elementos presentes em espécies de vários clados da família. Análises foram feitas usando parcimônia de Fitch, com caracteres binários, não ordenados e não polarizados (Wiley et al. 1991) no programa Mesquite 1.1. Espécies, gêneros ou clados, da esquerda para direita, são: Lepidothrix serena, L. suavissima, L. coronata, L. isidorei, L. iris, Dixiphia pipra, Machaeropterus, clado de Pipra erythrocephala, clado de P. aureola, Heterocercus, Manacus, Chiroxiphia, clado de Ilicura e Neopelma.

Figure 2. Phylogenetic reconstruction of the evolution of behavioral elements (a) exclusives from Lepidothrix coronata, (b) shared within Lepidothrix species, and (c) similar to elements present in species from various clades in the family. Analysis were made using Fitch parsimony, with binary characters, unordered and not polarized (Wiley et al. 1991) in Mesquite 1.1 software. Species, genera or clades, from left to right, are: L. serena, L. suavissima, L. coronata, L. isidorei, L. iris, Dixiphia pipra, Machaeropterus, P. erythrocephala clade, P. aureola clade, Heterocercus, Manacus, Chiroxiphia, Ilicura and Neopelma clades. 
Ainda que escassos, estudos que associam o desvio em sucesso reprodutivo de machos a variações em seus comportamentos de corte indicam que machos que exibem taxas elevadas de vocalizações ( $L$. coronata, Durães et al. 2008), ou vocalizações em coordenação entre machos cooperativos (Chiroxiphia, McDonald 1989, ver também Duval 2007) obtém maior sucesso reprodutivo. Estes resultados indicam que diferenças entre espécies e populações em características do comportamento de corte, juntamente com as características da organização espacial e estrutura social em leques, podem indicar diferenças na magnitude de desvio no sucesso reprodutivo observada entre machos de uma população. É possível testar comparativamente, por exemplo, a associação de variações entre aspectos espaciais e comportamentais na família. Estudos abordando efeitos de variação em comportamento de machos para seu sucesso reprodutivo irão contribuir para a compreensão do efeito da seleção sexual na elaboração destas características, e suas consequências evolutivas para populações e espécies. Assim, é possível testar ainda como o grau de diferenciação, bem como a complexidade de exibições, afetam a variação em sucesso reprodutivo entre machos de diferentes espécies.

\section{CONSERVAÇÃO DE PIPRÍDEOS AMAZÔNICOS}

Apesar dos piprídeos frequentemente apresentarem densidades populacionais médias a elevadas (Ridgely \& Tudor 1994, Snow 2004) e aparentemente não sofrerem efeitos da fragmentação florestal (Anciães \& Marini 2000), a organização espacial e dinâmica populacional em seus sistemas de leques sugere a necessidade de grandes áreas para a persistência de populações viáveis, uma vez que tanto fêmeas e machos jovens utilizam grandes áreas de vida (Graves et al. 1992, Théry 1992, Rosselli et al. 2002, Anciães \& Marini 2002, Anciães \& Del Lama 2002). A fragmentação florestal pode, portanto, afetar a dinâmica populacional de piprídeos através do isolamento de indivíduos e aumento de suas densidades em leques (Anciães et al. 2005). As espécies do gênero Lepidothrix com distribuições relativamente restritas já foram previstas a entrar no rol de espécies ameaçadas no cenário atual de desenvolvimento na Amazônia (Vale et al. 2008); entretanto, a diversidade ainda sendo reconhecida dentro de espécies de ampla distribuição, mas com bastante variação geográfica, como Lepidothrix coronata, pode também estar ameaçada. Alem disso, as previsões climáticas para o futuro sugerem que os piprídeos da Amazônia sofrerão extinções locais devido à perda de seus hábitats (Anciães \& Peterson 2006), tornando prioritário que se protejam áreas com elevado potencial de preservação de diversidade biológica.

Existe assim uma grande necessidade de estudos ornitológicos em localidades da Amazônia que abranjam táxons de relevante interesse biogeográfico (ex., conhecidamente distribuídos em margens opostas de principais rios da região) e enfoquem aspectos multidisciplinares que permitam a avaliação de hipóteses alternativas para explicar os padrões de distribuição observados em uma região. O maior número de estudos biogeográficos na Amazônia irá permitir uma avaliação de enfoque comparativo, sobre táxons co-distribuídos, que permita compreender a formação das distribuições geográficas atuais. Tais estudos não apenas contribuirão para o avanço científico nas áreas de biogeografia, evolução e ecologia da biota amazônica, como também fornecerão subsídios para a conservação da diversidade biológica da região, uma vez que indicarão processos que afetam a diversificação taxonômica, e que, portanto, devem ser considerados em planos de manejo e conservação (Soulé \& Simberloff 1986), e a distribuição da diversidade a ser contemplada em unidades de conservação.

\section{CONSIDERAÇÕES FINAIS}

Estudos adicionais com marcadores moleculares nucleares, bem como do cromossomo-Y (Cheviron et al. 2005) poderão testar a presença de introgressão na região indicada como zona de contato em $L$. coronata, os quais devem concentrar esforços em localizar possíveis populações mistas para estudar preferências de fêmeas, bem como avaliar a variação geográfica em comportamento de corte e utilização espacial pelos indivíduos de sexos opostos. Tais estudos são também necessários para avaliar a variação entre haplótipos na zona de contato, sobretudo na região do baixo rio Juruá, e entre os rios Jutaí e Ucayali, no Peru.

A topologia recuperada pelo nosso estudo com L. coronata apresenta estrutura e resolução similares àquela apresentada por Cheviron et al. (2005), sendo recuperados dois clados principais. O primeiro, com 
suporte (valor de bootstrap) de 78\%, distribui-se ao norte dos rios Solimões e Japurá. Este se subdivide em um clado distribuído à margem direita do rio Negro (suporte de 78\%) e outro localizado à sua margem esquerda (83\%). O segundo clado principal, com suporte de 96\%, distribui-se ao sul dos rios Japurá e Solimões, sendo dividido em um clado localizado entre os rios Japurá e Solimões (100\%), e outro (61\%) extendendo-se entre os rios Ucayali, no Peru, e Madeira, no Brasil. Entretanto, a falta de táxons em nosso estudo produz uma topologia polifilética para o segundo clado principal e, assim, aguardamos a inclusão de mais amostras, bem como marcadores moleculares, para apresentação de dados completos. Esperamos reduzir os efeitos de baixo poder de teste em análises de história demográfica do grupo, o qual deve explicar os resultados contraditórios sobre as populações distribuídas à margem direita do rio Negro, bem como daquelas localizadas no interflúvio Japurá-Solimões. Estas populações são muito provavelmente exemplares de um clado que se extende consideravelmente a oeste e noroeste, dentre aqueles recuperados em Cheviron et al. (2005), e, portanto, os índices encontrados para tal grupo de populações não devem representar a composição haplotípica de seu clado como um todo.

Homologizar (i. é., designar similaridade por ancestralidade) caracteres comportamentais é uma tarefa difícil. Não somente deve-se interpretar características comportamentais descritas em estudos conduzidos por diversos observadores e redatores (Bostwick 2000), bem como se deve levar em consideração as similaridades entre elementos comportamentais que podem ser agrupados e desagrupados dependendo do refinamento das descrições. Os elementos de corte podem ser decompostos, ou considerados como uma sequência integrada que definem uma exibição. Podem ainda ser exibidos na natureza por completo, ou parcialmente, com ou sem ordem definida (Martins 1996).

Os saltos e vôos exibitórios em Corapipo, Masius e Ilicura (Snow \& Snow 1985, Prum 1986, Prum \& Johnson 1987, Théry 1990, Rosselli et al. 2002), por exemplo, podem ser observados como uma sequência de aproximação dos palcos geralmente seguida por saltos com uma ou duas cambalhotas. Cada parte desta exibição (assim descrita na literatura) pode ser observada separadamente (M. Anciães, observ. pess.), inclusive as cambalhotas com emissão dos sons mecânicos típicos de exibições de aproximação de palcos (ex., "log-approach-displays”). A trajetória de vôos borboleta e a postura corporal e batimento de asas usadas em vôos tipo "S", são exemplos ainda de variações que podem facilmente ser integradas ou separadas durante a definição de elementos homólogos. Assim, os dados comportamentais aqui apresentados resumem uma interpretação, ou uma hipótese de evolução destas características.

É importante ressaltar ainda que a reconstrução de caracteres ancestrais conforme apresentada, reunindo as espécies externas ao gênero Lepidothrix em clados principais (conforme Prum 1990 e Rêgo et al. 2007) não expressa as características ancestrais dos mesmos, mas o conjunto de elementos presentes nestes clados. Apenas uma análise detalhando o comportamento de cada espécie, aliada ao uso de uma hipótese filogenética consensual de parentesco entre estas, poderá indicar a ancestralidade dos elementos apresentados (Tabela II).

Por fim, estes dados indicam que a seleção sexual não somente é responsável pela elaboração morfológica e comportamental na família, como também contribui para a diferenciação entre histórias de vida em linhagens evolutivas. Investigar padrões de variação morfológica e comportamental, bem como aspectos da organização social e espacial, em escala microevolutiva, portanto, nos permitirá compreender melhor a história demográfica de populações. São escassos ainda estudos que comparem repertórios e sucesso reprodutivo entre machos, sendo estes indicados como estudos necessários em escala populacional. Em escala regional, estudos em zonas de contato, por exemplo, oferecem oportunidade para compreendermos a importância da variação em preferência de fêmeas e interações entre machos na disseminação de genes em introgressão. Assim, compreenderemos a relevância da seleção sexual na formação de linhagens evolutivas independentes na família.

AGRADECIMENTOS: Financiamentos (FAPEAM, CNPq, CAPES), licenças de pesquisa (IBAMA, SDS), Fundação Vitória Amazônica, Coleções zoológicas (INPA, MNRJ, MZUSP, AMNH, NMNH, LSUMNH, FMNH), discussões e colaboração (Richard Prum, Town Peterson, Zac Cheviron, Bette Loiselle, David McDonald, Mercival Francisco, Gisella Gacone, Phil Stoufer, Erik Johnson, Kari Schmidt, Luciano Naka e Cathy Bechtoldt), trabalho de campo e laboratório (Mariana Tolentino, Jefferson Valsko, Shizuka Hashimoto, Waleska Gravena, Concy Santos). Esta é a contribuição número 11 na Série Técnica em Ornitologia Amazônica do Programa de Coleções do INPA. 


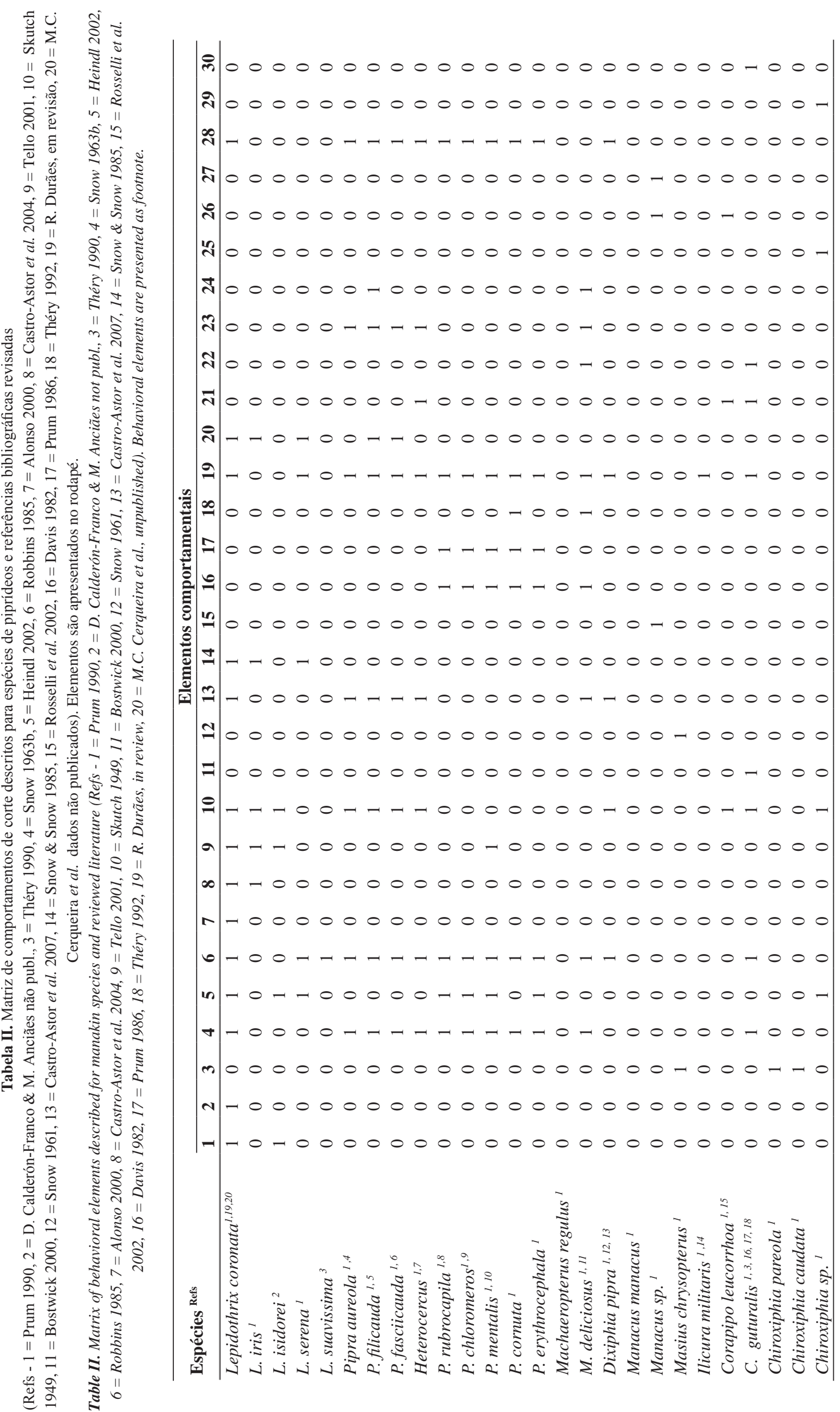




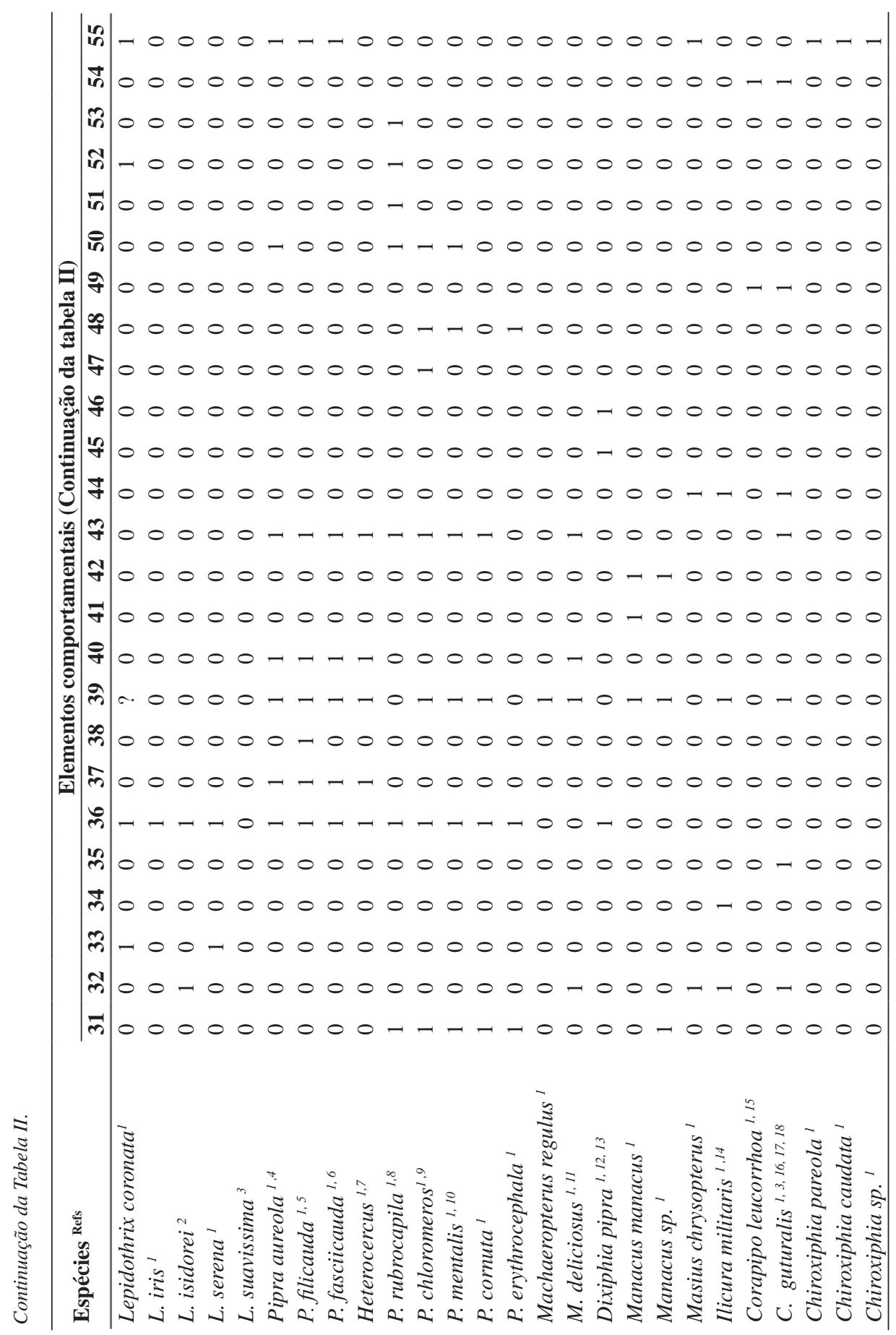

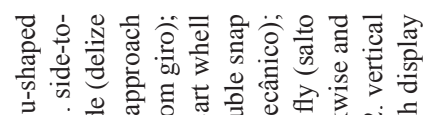

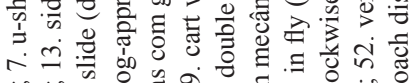

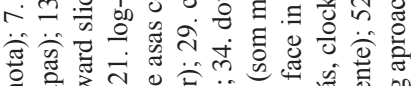

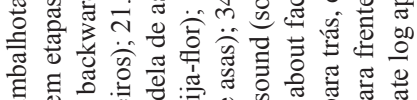

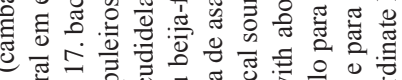

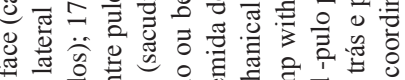



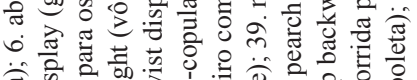

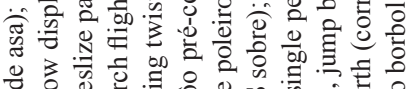

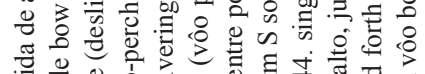

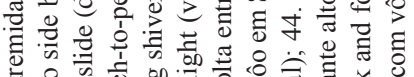

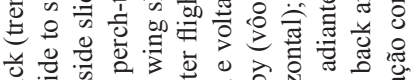

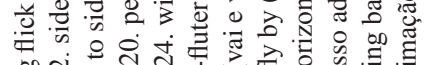
焉

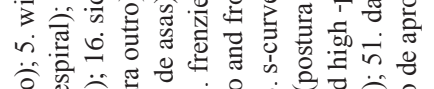

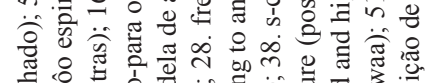

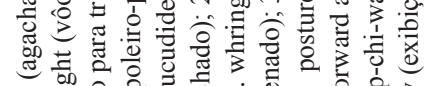

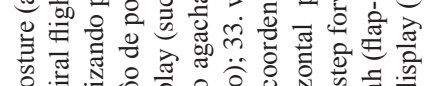

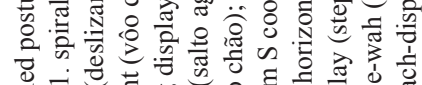

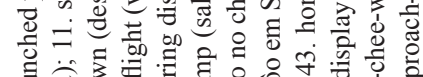

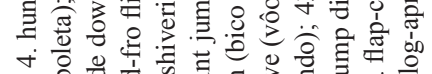

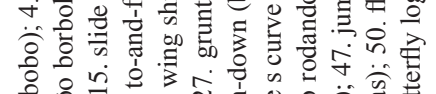

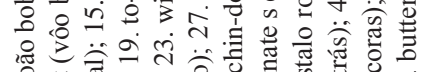

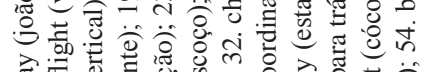

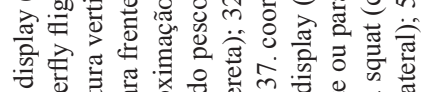

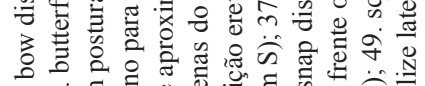

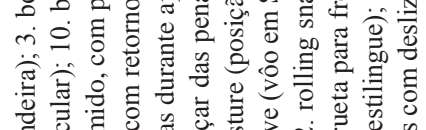

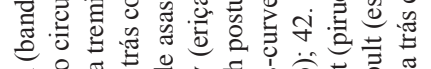

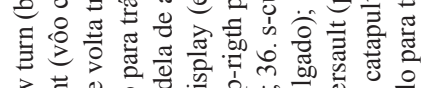

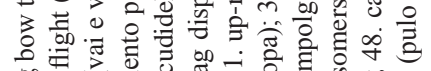

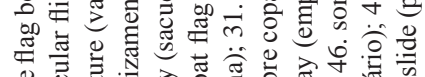

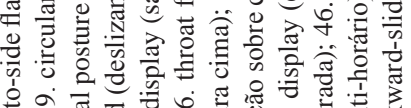

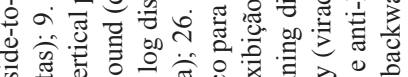

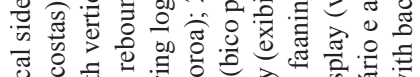

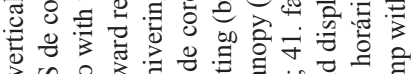

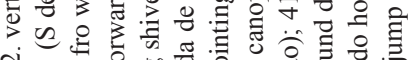

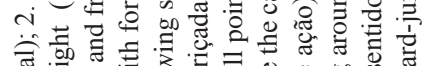

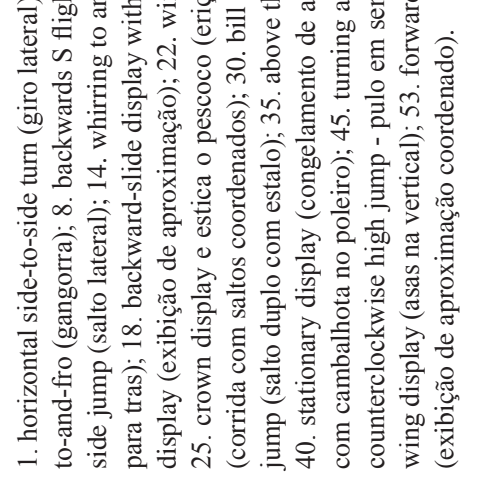




\section{REFERÊNCIAS}

ALEIXO, A. 2004. Historical diversification of a terra-firme forest bird superspecies: a phylogeographic perspective on the role of different hypotheses of Amazonian diversification. Evolution, 58: 1303-1317.

ALONSO, J.A. 2000. The breeding system of the Orangecrowned Manakin. Condor, 102: 181-186.

ANCIÃES, M. 2005. Evolution of visual signals and the ecological niches among Manakins (Aves: Pipridae) from the Ilicura-Corapipo clade. Ph.D. dissertation. The University of Kansas, Lawrence, KS. 214p.

ANCIÃES, M. \& DEL LAMA, S.N. 2002. Sex identification of Pin-tailed Manakins (Ilicura militaris: Pipridae) using Polymerase Chain Reaction and its applications to behavioral studies. Ornitologia Neotropical, 13: 159-165.

ANCIÃES, M., \& MARINI, M.Â. 2000. The effects of fragmentation on fluctuating asymmetry in passerine birds of Brazilian tropical forests. Journal of Applied Ecology, 37: 1013-1028.

ANCIÃES, M. \& MARINI, M.Â. 2002. Spatial and social organization of Pin-tailed Manakins (Aves: Pipridae): inferences from mist-net data. Annual Meeting of the Animal Behaviour Society, Bloomington, IN. 107p.

ANCIÃES, M. \& PETERSON, A.T. 2006. Climate change effects on Neotropical manakin diversity based on ecological niche modeling. Condor, 108: 778-791.

ANCIÃES, M. \& PRUM, R.O. 2008. Manakin display and visiting behaviour: a comparative test of sensory drive. Animal Behaviour, 75: 783-790.

ANCIÃES, M.; NEMÉSIO, A. \& SEBAIO, F. 2005. A case of plumage aberration in the Pin-tailed Manakin Ilicura militaris. Cotinga, 23: 39-43.

ANDERSSON, M. 1994. Sexual selection. Princeton University Press, Princeton, New Jersey. 599p.

AVISE, J.C. 2000. Phylogeography: the history and formation of species. Harvard University Press, Cambridge. 447p.

BATES, J.M. 2000. Allozymic genetic structure and natural habitat fragmentation: data for five species of Amazonian forest birds. Condor, 102: 770-783.

BATES, J.M. 2001. Avian diversification in Amazonia: evidence for historical complexity and a vicariance model for a basic pattern of diversification. Pp. 119-138. In: I. Vieira, M.A. D’Incao, J.M. C. Silva \& D. Oren (eds.). Diversidade Biológica e Cultural da Amazônia. Museu Paraense Emilio Goeldi, Belém, Brazil. 421p.
BATES, J.M.; HACKETT, S.J. \& GOERCK, J.M. 1999. High levels of mitochondrial DNA differentiation in two lineages of antbirds (Drymophila and Hypocnemis). Auk, 116: 1093-1106.

BATES, J.M.; HAFFER, J. \& GRISMER, E. 2004. Avian mitochondrial DNA sequence divergence across a headwater stream of the Rio Tapajós, a major Amazonian river. Journal for Field Ornithology, 145: 199-205.

BEEHLER, B.M \& FOSTER, M.S. 1988. Hotshots, hotspots, and female preference in the organization of lek mating systems. American Naturalist, 131: 203-219.

BOSTWICK, K.S. 2000. Display behaviors, mechanical sounds, and evolutionary relationships of the Club-winged Manakin (Machaeropterus deliciosus). Auk, 112: 465-478.

BRADBURY, J.W. 1981. The evolution of leks. Pp. 138-169. In: R.D. Alexander \& D.W. Twinkle (eds.). Natural selection and social behavior. Chiron Press, New York, NY. 532p.

BRADBURY, J.W. \& GIBSON, R.M. 1983. Leks and mate choice. 109-140. In: P. Bateson (ed.). Mate choice. Cambridge University Press, Cambridge, UK. 480p.

BRADBURY, J.W; GIBSON, R.M \& TSAI, I.M. 1986. Hotspots and the dispersion of leks. Animal Behaviour, 34: 1694-1709.

BRADBURY，J.W.; GIBSON，R.M; MCCARTHY，C.E. \& VEHRENCAMP, S.L. 1989. Dispersion of displaying male sage grouse-II. The role of female dispersion. Behavioral Ecology and Sociobiology, 24: 15-24.

BRUMFIELD, R.T.; JERNIGAN, R.W.; MCDONALD, D.B. \& BRAUN, M.J. 2001. Evolutionary implications of divergent clines in an avian (Manacus: Aves) hybrid zone. Evolution, 55: 2070-2087.

CAPPARELLA, A.P. 1988. Genetic variation in neotropical birds: implications for the speciation process. Acta of the XIX International Ornithological Congress, 19: 1658-1664.

CAPPARELLA, A.P. 1991. Neotropical avian diversity and riverine barriers. Proceedings of the International Ornithological Congress, 20: 307-316.

CASTRO-ASTOR, I.N.; ALVES, M.A.S. \& CAVALCANTI, R.B. 2004. Display behavior and spatial distribution of the Red-headed Manakin in the Atlantic Forest of Brazil. Condor, 106: 320-335.

CASTRO-ASTOR, I.N.; ALVES, M.A.S. \& CAVALCANTI, R.B. 2007. Display behavior and spatial distribution of the whitecrowned manakin in the Atlantic forest of Brazil. Condor, 109: 155-166. 
CHAPMAN, F.M. 1917. The distribution of bird-life in Colombia Bulletin of the American Museum of Natural History, 36: 1-729.

CHEVIRON, Z.A.; HACKETT, S.J. \& CAPPARELLA, A.P. 2005. Complex evolutionary history of a Neotropical lowland forest bird (Lepidothrix coronata) and its implications for historical hypotheses of the origin of Neotropical avian diversity. Molecular Phylogenetics and Evolution, 36: 338-357.

CHEVIRON, Z.A.; HACKETT, S.J. \& BRUMFIELD, R.T. 2006. Sequence variation in the coding region of the melanocortin-1 receptor gene (MC1R) is not associated with plumage variation in the blue-crowned manakin (Lepidothrix coronata). Proceedings of the Royal Society of London Series B, 273: 1613-1618.

COHN-HAFT, M. 2000. A case study in Amazonian biogeography: vocal and DNA-sequence variation in Hemitriccus flycatchers. Ph.D. Dissertation. Louisiana State University, Baton Rouge. 136p.

CRACRAFT, J \& PRUM, R.O. 1988. Patterns and processes of diversification: speciation and historical congruence in some Neotropical birds. Evolution, 42: 603-620.

CRACRAFT, J. 1985. Historical biogeography and patterns of differentiation within the South American avifauna: areas of endemism. Pp. 49-84. In: P.A. Buckley, M.S. Foster, E.S. Morton, R.S. Ridgely \& F.G. Buckley (eds.). Neotropical Ornithology. The American Ornithologists’ Union Press, Washington, DC. 1041p.

DARWIN, C. 1871. The descent of man and selection in relation to sex. Murray, London. 475p.

DAVIS, T.A. 1982. A flight-song display of the white-throated manakin. Wilson Bulletin, 94: 594-595.

DURÃES ，R.; LOISELLE，B.A. \& BLAKE，J.G. 2007. Intersexual spatial relationships in a lekking species: bluecrowned manakins and female hot spots. Behavioral Ecology, 18: 1029-1039.

DURÃES, R.; LOISELLE, B.A. \& BLAKE, J.G. 2008. Spatial and temporal dynamics at manakin leks: reconciling lek traditionality with male turnover. Behavioral Ecology and Sociobiology, 62: 1957-1967.

DUVAL, E.H. 2007. Adaptive advantages of cooperative courtship for subordinate male lance-tailed manakins. American Naturalist, 169: 423-432.

ENDLER, J.A. 1977. Geographic variation, speciation, and clines. Princeton University Press, Princeton, NJ. 262p.

ENDLER, J.A. 1992. Signals, signal condition and the direction of evolution. American Naturalist, 139: S125-S153.
ENDLER, J.A. \& THÉRY, M. 1996. Interacting effects of lek placement, display behavior, ambient light, and color patterns in three Neotropical forest-dwelling birds. American Naturalist, 148: 421-452.

FORMICA, V.A.; GONSER, R.A.; RAMSAY, S. \& TUTTLE, E.M. 2004. Spatial dynamics of alternative reproductive strategies: the role of neighbors. Ecology, 85: 1125-1136.

FOSTER, M. 1983. Disruption, dispersion and dominance in lek-breeding birds. American Naturalist, 122: 53-72.

FRANCISCO, M.R.; GALETTI, M.P. \& GALETTI JUNIOR, M.P. 2006. Atlantic forest fragmentation and genetic diversity of an isolated population of the Blue-manakin, Chiroxiphia caudata (Pipridae), assessed by microsatellite analyses. Revista Brasileira de Ornitologia, 14: 21-28.

FRANCISCO, M.R.; GIBBS, H.L.; LUNARDI, V.O.; GALETTI, M. \& GALETTI JUNIOR, P.M. 2007. Genetic structure in a tropical lek-breeding bird, the blue manakin (Chiroxiphia caudata) in Brazilian Atlantic Forest. Molecular Ecology, 16: 4908-4918.

GASCON, C.; LOUGHEED, S.C. \& BOGART, J.P. 1998. Patterns of genetic population differentiation in four species of Amazonian frogs: a test of the riverine barrier hypothesis. Biotropica, 30: 104-119.

GASCON, C.; MALCOLM, J.R.; PATTON, J.L.; SILVA, J.M.C.; BOGART, J.P.; LOUGHEED, S.C.; PERES, C.A.; NECKEL, S. \& BOAG, P.T. 2000. Riverine barriers and the geographic distribution of Amazonian species. Proceedings of the National Academy of Sciences of United States of America, 97: 13672-13677.

GRAVES, G.R.; ROBBINS, M.B. \& REMSEN Jr., J.V. 1992. Age and sexual differences is spatial distribution and mobility in manakins (Pipridae): Inferences from mist-netting. Journal of Field Ornithology, 54: 407-412.

GRINNELL, J. 1917. Field tests of theories concerning distributional control. American Naturalist, 51: 115-128.

GRINNELL, J. 1924. Geography and evolution. Ecology, 5: 225-229.

HACKETT, S.J. 1996. Molecular phylogenetics and biogeography of tanagers in the genus Ramphocelus (Aves). Molecular Phylogenetics and Evolution, 5: 368-382.

HAFFER, J. 1974. Avian speciation in tropical South America, with a systematic survey of the toucans (Ramphastidae) and jacamars (Galbulidae). Nuttall Ornithological Club, Cambridge, MA. 390p. 
HAFFER, J. 1992. On the 'river effect' in some forest birds of southern Amazonia. Boletim do Museu Paraense Emílio Goeldi, Série Zoologia, 8: 217-245.

HAFFER, J. and PRANCE, G.T. 2001. Climatic forcing of evolution in Amazonian during the Cenozoic: on the refuge theory of biotic differentiation. Amazoniana, 16: 579-607.

HARPENDING, H. 1994. Signature of ancient population growth in a low resolution mitochondrial mismatch distribution. Human Biology, 66: 131-137.

HEINDL, M. 2002. Social organization on leks of the Wire-tailed Manakin in Southern Venezuela. Condor, 104: 772-779.

HELLMAYR, C.E. 1929. Catalogue of Birds of the Americas and the adjacent islands. Field Museum Natural History Publication Zoological Series. no. 6. Field Museum of Natural History, Chicago, IL. 258p.

HÖGLUND, J. \& ALATALO, R. 1995. Leks. Monographs in Behavior and Ecology. Princeton University Press, New Jersey. 1230p.

HUTCHINSON, G.E. 1957. Concluding remarks. Cold Spring Harbor Symposia on Quantitative Biology, 22: 415-427.

LANCTOT, R.B.; SCRIBNER, K.T.; KEMPENAERS, B. \& WEATHERHEAD, P.J. 1997. Lekking without a paradox in the buff-breasted sandpiper. American Naturalist, 149: 1051-1070.

LANK, D.B.; SMITH, C.M.; HANOTTE, O.; OHTONEN, A.; BAILEY, S. \& BURKE, T. 2002. High frequency of polyandry in a lek mating system. Behavioral Ecology, 13:209-215.

LILL, A. 1976. Lek behavior in the Golden-headed Manakin (Pipra erythrocephala) in Trinidad (West Indies). Zeitschrift für Tierpsychologie, 18 (Suppl.): 1-84.

LOISELLE, B.A.; BLAKE, J.G.; DURÃES, R.; RYDER, T.B. \& TORI, W.P. 2007. Environmental segregation in lek sites among six co-occurring species of manakins (Aves: Pipridae) in eastern Ecuador. Auk, 124: 420-431.

MACARTHUR, R. 1972. Geographical ecology: patterns in the distribution of species. Princeton University Press, Princeton, N.J. 269p.

MACKENZIE, A.; REYNOLDS, J.D.; BROWN, V.J. \& SUTHERLAND, W.J. 1995. Variation in male mating success on leks. American Naturalist, 145: 633-652.

MARKS, B.D.; HACKETT, S.J. \& CAPPARELLA, A.P. 2002. Historical relationship among neotropical lowland forest areas of endemism as determined by mitochondrial DNA sequence variation within the wedge-billed woodcreeper
(Aves: Dendrocolaptidae: Glyphorynchus spirurus). Molecular Phylogenetics and Evolution, 24: 153-167.

MARTÍNEZ-MEYER, E.; PETERSON, A.T. \& HARGROVE, W.W. 2004. Ecological niches as stable distributional constraints on mammal species, with implications for Pleistocene extinctions and climate change projections for biodiversity. Global Ecology and Biogeography, 13: 305-314.

MARTINS, E. P. 1996. Phylogenies and the comparative method in animal behavior. Oxford University Press, New York, NY. 1640p.

MCDONALD, D.B. 1989. Correlates of male mating success in a lekking bird with male-male cooperation. Animal Behavior, 37: 1007-1022.

MCDONALD, D.B. \& POTTS, W.K. 1994. Cooperative display and relatedness among males in a lek-mating bird. Science, 266: 1030-1032.

NEI, M. 1987. Molecular evolutionary genetics. Columbia University Press, NY. 292p.

PATTON, J.L.; DA SILVA, M.N.F. \& MALCOLM, J.R. 1994. Gene genealogy and differentiation among arboreal spiny rats (Rodentia: Echmyidae) of the Amazon: a test of the riverine barrier hypothesis. Evolution, 48: 1314-1323.

PATTON, J.L.; DA SILVA, M.N.F.; LARA, M.C.; \& MUSTRANGI, M.A. 1997. Diversity, differentiation, and the historical biogeography of nonvolant small mammals of the Neotropical forests. Pp. 455- 465. In: W.F. Laurence \& R.O. Bierregaard Jr. (eds.). Tropical forest remnants: ecology, management, and conservation of fragmented communities. University of Chicago Press, Chicago, Il. 632p.

PATTON, J.L. \& DA SILVA, M.N.F. 1998. Rivers, refuges, and ridges: the geography of speciation of Amazonian mammals. Pp. 202-213. In: D.J. Howard \& S.H. Berlocher (eds.). Endless forms: species and speciation. Oxford University Press, Oxford, U.K. 496p.

PATTON, J.L.; DA SILVA, M.N.F. \& MALCOLM, J.R. 2000. Mammals of the Rio Juruá and the evolutionary and ecological diversification of Amazonia. Bulletin of the American Museum of Natural History, 244: 1-306.

PAYNE, R.B. 1984. Sexual selection, lek and arena behavior, and sexual size dimorphism in birds. Ornithological Monographs 33. American Ornithologists's Union, Washington, DC. 52p.

PETERSON, A.T.; SOBERÓN, J. \& SANCHEZ-CORDERO, V. 1999. Conservatism of ecological niches in evolutionary time. Science, 285: 1265-1267. 
PIRES, J.M. \& PRANCE, G.T. 1985. The vegetation types of the Brazilian Amazon. Pp. 109-145. In: G.T. Prance \& T.E. Lovejoy Key environments: Amazonia. Pergamon Press, Oxford. 442p.

PRUM, R.O. 1986. The displays of the white-throated manakin Corapipo gutturalis in Suriname. Ibis, 128: 91-102.

PRUM, R.O. 1990. Phylogenetic analysis of the evolution of display behavior in the Neotropical manakins (Aves: Pipridae). Ethology, 84: 202-231.

PRUM, R.O. 1992. Syringeal morphology, phylogeny, and evolution of the neotropical manakins (Aves: Pipridae). American Museum of Natural History Novitates, 3043: 1-65.

PRUM, R.O. 1997. Phylogenetic tests of alternative intersexual selection mechanisms: Trait macroevolution in a polygynous clade (Aves: Pipridae). American Naturalist, 149: 668-692.

PRUM, R.O. 1998. Sexual selection and the evolution of mechanical sound production in manakins (Aves: Pipridae). Animal Behaviour, 55: 977-994.

PRUM, R.O. \& JOHNSON, A.E. 1987. Display behaviour, foraging ecology, and systematics of the golden-winged manakin (Masius chrysopterus). Wilson Bulletin, 99: 521-539.

RÊGO, P.S.; ARARIPE, J.; MARCELIANO, M.L.V.; SAMPAIO, I. \& SCHNEIDER, H. 2007. Phylogenetic analyses of the genera Pipra, Lepidothrix and Dixiphia (Pipridae, Passeriformes) using partial cytochrome b and 16S mtDNA genes. Zoologica Scripta, 36: 1-11.

RICE, N.H.; MARTÍNEZ-MEYER, E. \& PETERSON, A.T. 2003. Ecological niche differentiation in the Aphelocoma jays: a phylogenetic perspective. Biological Journal of the Linnean Society, 80: 369-383.

RIDGELY, R.S. \& TUDOR, G. 1994. The Birds of South America. Vol. 2. University of Texas Press, Austin, TX. 814p.

ROBBINS, M.B. 1985. Social organization of the Band-tailed Manakin (Pipra fasciicauda). Condor, 87: 449-456.

ROMIS-ONSINS, S.E. \& ROZAS, J. 2002. Statistical properties of new neutrality tests against population growth. Molecular Biology and Evolution, 19: 2092-2100.

ROSSELLI, L.; VASQUEZ, P. \& AVUB, I. 2002. The courtship displays and social system of the White-ruffed Manakin in Costa Rica. Wilson Bulletin, 114: 165-178.

RYDER, T.B.; BLAKE, J.G \& LOISELLE, B.A. 2006. A test of the environmental hotspot hypothesis for lek placement in three species of manakins (Pipridae) in Ecuador. Auk, 123: 247-258.
SARDELLI, C.H. 2005. Variação genética e geográfica de Hemitriccus minor (Aves-Tyrannidae) na Bacia do Madeira, AM/Brasil. Dissertação de mestrado. INPA, Manaus, Amazonas, Brasil. 55p.

SHUSTER, S.M. \& WADE, M.J. 2003. Mating systems and strategies. Monographs in behavior and ecology. Princeton University Press, Princeton, New Jersey. 533p.

SICK, H. 1967. Courtship behavior in manakins (Pipridae): a review. Living Bird, 6: 5-22.

SILVA,M.N.F.\&PATTON, J.L.1998. Molecularphylogeography and the evolution and conservation of Amazonian mammals. Molecular Ecology, 7: 475-486.

SKUTCH, A.F. 1949. Life history of the Yellow-thighed Manakin. Auk, 66:1-24.

SNOW, D.W. 1961. The display of manakins Pipra pipra and Tyranneutes virescens. Ibis, 103: 110-113.

SNOW, D.W. 1963a. The Evolution of manakin courtship display. Proceedings of the International Ornithological Congress, 13: 553-561.

SNOW, D.W. 1963b. The display of the Orange-headed manakin. Condor, 65: 44-48.

SNOW, D.W. 2004. Family Pipridae (Manakins). Pp. 110-169. In: J. del Hoyo, A. Elliott \& D.A. Christie (eds.). Handbook of the Birds of the World. Vol. 9. Cotingas to Pipits and Wagtails. Lynx Editions, Barcelona. 863p.

SNOW, B.K \& SNOW, D.W. 1985. Display and related behavior of male Pin-tailed manakins. Wilson Bulletin, 97: 273-282.

SOBERÓN, J. \& PETERSON, A.T. 2005. Interpretation of models of fundamental ecological niches and species' distributional areas. Biodiversity Informatics, 2: 1-10.

SOULÉ, M.E. \& SIMBERLOFF, D.S. 1986. What do genetics and ecology tell us about the design of nature reserves? Biological Conservation, 35: 19-40.

STEIN A.C., \& UY, J.A.C. 2006a. Unidirectional introgression of a sexually selected trait across an avian hybrid zone: a role for female choice? Evolution, 60: 1476-1485.

STEIN, A.C. \& UY, J.A.C. 2006b. Plumage brightness predicts male mating success in the lekking golden-collared manakin. Behavioral Ecology, 17: 41-47.

STODDARD, M.C. \& PRUM, R.O. 2008. Evolution of avian plumage color in a tetrahedral color space: a phylogenetic analysis of New World Buntings. American Naturalist 171: 755-776. 
TELLO, J.G. 2001. Lekking behavior of the Round-tailed Manakin. Condor, 103: 298-321.

THÉRY, M. 1990. Display repertoire and social organization of the White-fronted and White-throated manakins. Wilson Bulletin, 102: 123-130.

THÉRY, M. 1992. The evolution of leks through female choice: differential clustering and space utilization in six sympatric manakins. Behavioral Ecology and Sociobiology, 30: 227-237.

TORI, W.P.; DURÃES, R.; RYDER, T.B.; ANCIÃES, M.; KARUBIAN, J.; MACEDO, R.H.; UY, J.A.C.; PARKER, P.G.; SMITH, T.B.; STEIN, A.C.; WEBSTER, M.S.; BLAKE, J.G. \& LOISELLE, B.A. 2008. Advances in sexual selection theory: insights from tropical avifauna. Ornitologia Neotropical, 19 (Suppl.): 151-163.

UY, J.A.C. \& ENDLER, J.A. 2004. Modification of the visual background increases the conspicuousness of golden-collared manakin displays. Behavioral Ecology, 15: 1003-1010.

VALE, M.V.; COHN-HAFT, M.; BERGEN, S. \& PIMM, S.L. 2008. Effects of future infrastructure development on threat status and occurrence of Amazonian birds. Conservation Biology, 22: 1006-1015.

WALLACE, A.R. 1852. On the monkeys of the Amazon. Proceedings of Zoological Society of London, 20:107-110.

WESTCOTT, D.A. 1994. Lek location and patterns of females movement and distribution in a Neotropical frugivorous bird. Animal Behaviour, 53: 235-247.

WILEY, E.O.; SIEGEL-CAUSEY, D.; BROOKS, D.R. \& FUNK, V.A. 1991. The complete cladist, a primer of phylogenetic systematics. The University of Kansas Museum of Natural History Special Publication No.19. The University of Kansas Printing Service, Lawrence, KS. 158p.

Submetido em 24/09/2008.

Aceito em 20/11/2008. 